\title{
ENVIRONMENTAL ACTIVISM AND THE CONSTRUCTION OF RISK: IMPLICATIONS FOR NGO ALLIANCES
}

\author{
TIMOTHY FORSYTH* \\ Institute of Development Studies, Brighton, UK
}

\begin{abstract}
This paper argues that academic approaches to environmental policy that equate political pluralism with the representation of plural environmental rationalities are overoptimistic and avoid the complex ways in which risk is constructed. The paper discusses two cases of industrial poisoning in Thailand to illustrate how alliances between factory workers and middle class activists strengthened political campaigns against the state but failed to identify the nature of risk or address workers' concerns. It is argued that academic debates need to acknowledge the pragmatic nature of both environmental knowledge and NGO alliances, and therefore seek more effective, inclusive public fora for assessing risk. Copyright (C) 1999 John Wiley \& Sons, Ltd.
\end{abstract}

\section{INTRODUCTION}

Since the Rio Earth Summit in 1992, there has been a wealth of attention to the role of non-governmental organizations (NGOs) and an active civil society in environmental policy. NGOs and other citizen groups have been seen as ways to enhance democratization and empower local groups as both adopters and formulators of environmental policy. At the same time there has been a revolution in approaches to environmental knowledge which has highlighted the ability of environmental movements to question dominating discourses of development (e.g. Apffel, Marglin and Marglin, 1990). Increasingly, poststructural theorists are using concepts such as 'citizen science' (Irwin, 1995) or 'liberation ecology' (Peet and Watts, 1996) to indicate not only the political significance of civil society in challenging the state, but also the epistemological value in redefining which problems are to be addressed.

However, this optimistic approach to NGOs and civil society is now being questioned by researchers who argue that environmental activism itself may have

* Correspondence to: Timothy Forsyth, Environment Group, Institute of Development Studies, Falmer, Brighton BN1 9RE, UK. e-mail: t.forsyth@ids.ac.uk

CCC 0954-1748/99/050687-14\$17.50

Copyright (C) 1999 John Wiley \& Sons, Ltd. 
epistemological impacts that are detrimental to development (e.g. Eyerman and Jamison, 1991; Yearley, 1996). In particular, critics question how NGOs, or alliances between NGOs and other organizations, may successfully enhance democratization by representing the diverse voices contained in the alliance. In addition, they also question how alliances may assist in understanding complex biophysical processes that constitute environmental risk. Critics do not doubt the underlying need to enhance civil society as a way to strengthen environmental policy. But they do question the automatic assumption that NGO alliances may necessarily maximise benefits to poorer members of society or increase environmental expertise.

This paper contributes to the debate by reviewing arguments concerning NGO alliances and the construction of risk, and then applying them to two related incidents of industrial poisoning and environmental activism in Thailand. The paper asks two questions: 'how do NGO alliances assist in the identification of biophysical risk?', and 'how do alliances between different social groups impact on the political representation of each group?'. The paper is relevant to existing debates about the social construction of science (Wynne, 1996) as well as the political impacts of NGO alliances and civil society (Covey, 1995; Putzel, 1997).

The paper is divided into three main sections. Firstly, the paper reviews debates about environmental activism and the production of environmental knowledge. Secondly, it describes the details of the case studies in Thailand. Thirdly, it discusses the relevance of the case studies for debates. The paper's key argument is that environmental activism itself may not assist the identification of risk, or assist the poorest members of society.

\section{NGO ALLIANCES AND THE PRODUCTION OF ENVIRONMENTAL KNOWLEDGE}

Academic approaches to the role of NGO alliances in environmental policy are undergoing a transition from a focus on NGOs as political actors towards an analysis of their impact on the generation and communication of knowledge (e.g. Hajer, 1995). The aim of this paper is to argue that environmental activism involving alliances between NGOs or other citizen groups may in fact restrict the communication of local knowledge to the policy arena.

Since the 1980s, an active civil society has been seen to be an essential requirement for democratization and the development of an equitable environmental policy. Agenda 21, for example, has stressed that grassroots organizations (GROs) may work alongside local, national or international NGOs in either implementing environmental policy or in communicating local concerns to the decision-making authorities (Paehlke and Torgerson, 1990). Environmental activism involving NGOs and GROs has also resisted threats to local livelihoods resulting from state or industry action. Alliances between NGOs and other citizen groups have formed an essential strategy in either increasing scientific expertise about alleged environmental risks, or in gaining added cohesion for campaigns across different sectors of society. As Princen et al. (1994, p. 226) wrote: 'NGOs are increasingly prominent forces in framing environmental issues. They help establish a common language and, sometimes, common world views'. 
Yet increasingly, the overt political role of NGOs and activisits in challenging state and industry interests has been supplemented by the epistemological impacts on redefining the nature and purpose of environmental policy. Poststructuralist theorists have pointed to activism from NGOs or other groups as forms of postmodern politics, in which the agendas and assumptions guiding environmental policy may be challenged on the basis of local beliefs or alternative visions of development. Indeed, NGO networks and local activism have been instrumental in challenging so-called dominating discourses of development built upon historic approaches to modernization without regard to social differentiation (Apffel, Marglin and Marglin, 1990).

In environmental policy, three key concepts illustrate this transition from NGOs as 'political' to 'knowledge' actors. Firstly, research on so-called 'environmental orthodoxies' or 'environmental narratives' have indicated how historic scientific methods and research programmes under colonialism have created scientific laws about environmental change that may not be accurate under all conditions or represent the interests of poor people in developing countries (see Roe, 1995; Leach and Mearns, 1996). Examples of orthodoxies include crisis models of deforestation and desertification which avoid the ability for local groups to withstand environmental degradation, or the diverse environmental perceptions - or 'plural rationalities' — that exist at the local level. Citizen groups such as NGOs can therefore increase the representation of new environmental knowledge and agendas into the policy arena, and therefore work to overcome dominating discourses of environmental degradation (Brown and Ashman, 1996).

Secondly, Irwin (1995) coined the phrase 'citizen science' in Europe to refer to the greater inclusivity of the public in environmental and technological decision making. Public participation may result in the identification of new risks previously undetected by the institutionalized scientific bodies, plus assist in developing new ways to communicate environmental protection to people in terms they find comprehensible and trustworthy. Irwin argues there is a need to avoid using terms such as 'expert' and 'lay' knowledge because these reflect the historic social processes that led to the labelling of such groups. For this reason, Irwin rejects Funcowicz and Ravetz's (1993) similar term of 'post-normal science' to describe public participation in science because the words suggest it may be abnormal to consult the public. Instead, greater consultation and participation by both scientifically trained personnel and local inhabitants, often including alliances between groups, may lead to the mutual creation of information about hazards and the addressing of local concerns.

Thirdly, Peet and Watts (1996) have argued for a theory of 'liberation ecology' in developing countries in which a poststructural approach to environment is combined with political action by social movements as a way to create new political spaces for local environmental management. The approach is underwritten by their belief in diversity of environmental perception and the need for local determination. They write (Peet and Watts, 1996, p. 37), 'the environment is an active construction of imagination, and the discourses themselves assume regional forms that are, as it were, theoretically organized by natural contexts. In other words, there is not an imaginary made in some "separate" social realm, but an environmental imaginary, or rather whole complexes of imaginaries with which people think, discuss, and contend threats to their livelihoods.' They argue social movements, including environmental activism, may create local spaces for environmental policy by effectively mobilizing local 
environmental knowledge as a political force. Social movements may also be assisted by organizations such as GROs, NGOs and their alliances.

Such concepts have indicated how academic research of environmental activism has transformed from a study of resource mobilization (or over political conflicts) alone towards the epistemological or cognitive impacts of activism (Eyerman and Jamison, 1991; Gandy, 1999). However, increasingly, the optimism associated with environmental activism and its ability to alter dominating discourses of environmental policy has been challenged. Critics have identified two main problems with the liberatory role of social movements and NGO activism.

Firstly, it is not clear how activism or alliances may successfully represent the diverse voices within an alliance, particularly the poorest or those furthest from the policy arena. This criticism reflects thinking from debates in subaltern discourse, or the difficulties of representing the opinions and knowledge of poor groups without replicating the agendas of the researcher or political activist (Spivak, 1988; Chambers, 1997). For example, Jackson (1995) has argued that women's resistance movements in India have been represented in a romanticist way that support Northern conceptions of nature rather than the local realities of local poor people. Similarly, Guha and Martinéz-Alier (1997) have described varieties of environmentalism between rich and poor in order to indicate the potential clashes between workers who claim access to resources, and urban or international élites who desire protection of wildlife or wilderness.

Secondly, it is also unclear how far activism may assist in understanding complex biophysical processes that constitute environmental risk. Much research under cultural ecology and 'citizen science' has highlighted that many farmers are indeed experts in land management. However, this expertise may decline under rapid industrialization where workforces have no historic experience of new technological risks such as industrial poisoning (although it is still possible for workers to have suggestions about the selection and placement of solutions - see the debate about malaria between Daly (1991) and Turnbull (1991)). Critical realist theorists have used this argument to criticize poststructural approaches to environment, and refer to it as the 'epistemic fallacy', or the mistaken assumption that people's experience of nature may accurately indicate the way in which nature operates independently of that experience (Searle, 1995; Bhaskar, 1986). Furthermore, it is also clear that NGOs and other organization may adopt political agendas themselves in the production and communication of knowledge. ${ }^{1}$

As a result of these criticisms, two key questions emerge. First, what are the implications of alliances between middle and working class activists for political campaigns? Covey (1995) has also argued that tensions between working and middleclass activists hide more fundamental divides between 'old' and 'new' social movements. Old social movements are associated with industrial societies and workingclass opposition to capital. New social movements, however, express new concepts of

\footnotetext{
${ }^{1}$ Boehmer-Christiansen (1994, p. 200), for example, assessed the impacts of alliances with 'expert' bodies sought by both US-government agencies and non-governmental environmental campaigners on the topic of global warming. She commented that engagement with 'independent' research institutions or NGOs engaged in major funding battles causes 'the exaggeration of knowledge claims, confirms existing national preferences, and stifles scientific debate.' She concluded '.... the research lobby, highly articulate and politically influential, has successfully manipulated the two poles of the postmodern environmental debate - ecoalarmism and ecological modernisation — to its own advantage.'
} 
identity such as environmentalism, feminism, sexuality and race which have been claimed to be classless and representative of developed, post-industrial societies (Eyerman and Jamison, 1991). While there has been some attention to new social movements in the South (Ponna, 1993), there is still much to be learnt about the tensions that develop when both old and new social movements emerge at the same time in rapidly industrializing societies. Alliances between working and middle-class environmental activists in developing countries may therefore see poor workers and farmers allying themselves with élites who not only have a different conception of environmentalism, but also who stand to gain most from the current economic system.

Second, how can activism increase the production of useful knowledge about environmental risk? Increasingly, sociologists of scientific knowledge are adopting insights from actor-network theory to illustrate how scientific 'facts' emerge as a result of complex historical relations between society and nature rather than through neutral positivist science (Long and Long, 1992; Murdoch and Clark, 1994). One important implication of this approach is that researchers themselves shape research according to different agendas (Jasanoff, 1996). Wynne (1996), however, has argued that researchers should avoid either 'taking sides' in conflicts or reduce debates to opposing 'sides' because this may limit the potential explanation of risk to those opinions that exist at present. Indeed, the topics of environmental conflict, such as deforestation or pollution, may themselves be 'epiphenomena', or short-term constructions which emerge as results of convergent (or so-called multivalent) aspects of discourse between actors, rather than from neutral and realist understandings of how these risks operate in biophysical terms (Hajer, 1995). Alliances between different political actors may therefore only serve to reflect deeper power relations in society rather than identify new and accurate indications of risk.

This paper attempts to consider these two questions by discussing the implications of cases of environmental activism concerning industrial poisoning in Thailand. The objective of the study is to indicate how far alliances between different actors influenced the construction of risk, and the political representation of factory workers. The case is also based on a piece of investigative journalism conducted by the author in 1994 (Forsyth, 1994) which also provides an opportunity to assess the role of the researcher in influencing the evolution of knowledge.

\section{CASE STUDY: INDUSTRIAL POISONING IN THAILAND}

Thailand is a fitting case study because, despite the financial crisis of 1997-98, it has been undergoing rapid industrialization and also the formation of a large network of environmental activists (see Hirsch, 1997). Alliances between grassroots activists and NGOs led to major environmental victories in 1988 with the cancellation of the Nam Choan dam and banning of logging in 1989 (Hirsch and Lohmann, 1989). In 1992, the country's first comprehensive environmental act was passed. The rapid success of environmentalism as a political force has encouraged some activists to claim it has been an important force for democratization. Withoon Permpongascharoen, the founder of the influential NGO, Project for Ecological Recovery, for example, has stated, 'environmental politics is about democratic politics' (Quigley, 1995, p. 1; also see Hewison, 1997). 
However, others have remained cautious about the ability for NGOs to overcome centuries of inequality. Rigg (1991; 1994, p. 16), for example states: "there is a need to critically evaluate the inclusion of environmental management into "alternative" development strategies by NGOs ... for the "alternative" ... has today become the "mainstream", and NGOs find themselves in the novel and rather uncomfortable position of representing the New Orthodoxy'. There is also evidence that middle-class activism for environmental protection and rural development may be based upon a romanticist perception of lost Thai heritage. Bamrung Bunpanya, one of the founders of the so-called wattamatham chumchon (community culture) movement, argued that 'village culture' was older, better, and more worthy of 'development' than cities, and could only be protected by self reliance from state or market dominance (Pasuk and Baker, 1995, p. 387).

The following example of environmental activism refers to two related incidents of alleged industrial poisoning.

\section{Samut Prakan, 1991}

In 1990, the Thai government created the National Institute for Occupational and Environmental Medicine (NIOEM) under the Ministry of Public Health. Its aim was to provide specialist research and treatment of industrial poisoning, and was allocated US $\$ 17.2 \mathrm{~m}$ under the seventh national and social development plan to establish a national network of offices with a staff of 200 .

The first investigation undertaken by NIOEM was in 1991 at a computer disc-drive factory in Samut Prakan owned by Seagate Technology Inc., the world's largest independent manufacturer of disc drives based in California. It located two factories in Thailand 1988-89, making it Thailand's largest foreign employer with some 16,000 staff (see Forsyth, 1994).

Four workers had died from unexplained circumstances, and campaigners suspected lead poisoning because of the use of lead soldering at the plant. Initial tests on blood samples from 1,175 factory workers revealed 36 per cent had more than 20 milligrams of lead per 100 millilitres of blood. This compared with contemporaneous studies showing similar figures of just 2 per cent for all Bangkok, and 8 per cent for Bangkok traffic police who are constantly exposed to traffic fumes. Although it was always known that these lead levels are generally not fatal, NIOEM suggested the high incidence may indicate that some workers had higher, possibly fatal, levels. Research was also undertaken to assess if workers had died from inhaling solvents used to clean electrical components.

Seagate denied responsibility for any lead poisoning, stating that their equipment heated lead to below the necessary $700^{\circ} \mathrm{C}$ to produce fumes. Yet this was later discounted by one doctor who stated that fumes may begin at $621.5^{\circ} \mathrm{C} .{ }^{3}$ Unfortunately for Seagate, rumours of possible lead poisoning reached the workforce who were

\footnotetext{
${ }^{2}$ Information in this section comes from a series of interviews undertaken 1994-95, initially as part of an investigative journalism project. Interviews were conducted in Thai or English in a unstructured form in person with informants for up to two hours. Informants were selected on the advice of interviewees and NGOs, and included representatives of NGOs, local action groups, government officials, medical doctors, and journalists. Newspaper reports were also used to supplement interviews.

${ }^{3}$ Dr Yvette Lolin, Department of Chemical Pharmacology, King George V Hospital, Hong Kong.
} 
already involved in an industrial dispute about unionization and wage levels. The result was an enhancement of strike action, leading to Thailand's largest industrial despute, with factory workers marching on parliament, petitioning President George Bush during his visit to Thailand, and the threat of sympathy action by workers in other industries. The Seagate workers did not form a new environmental organization or action group, but received assistance and publicity from national NGOs, notably the Friend of the Woman Foundation, and the Project for Ecological Recovery.

The strike caused concern among the government, who quickly sent in other technical agencies to conduct tests. The National Institute for the Improvement of Working Conditions and Environment, under the Ministry of Industry, this time took measurements of working conditions such as air and water rather than of workers' blood. They concluded Seagate had conducted no malpractice. However, it is unclear how far these tests were conducted without the prior knowledge of Seagate. In 1973, for example, the Japanese company Asahi was accused by environmentalists of discharging mercury into water. The Ministry of Health measured $2.718 \mathrm{ppm}$ in a local canal at nighttime without warning. The Ministry of Industry, meanwhile, measured just $0.003 \mathrm{ppm}$ after arriving at a prearranged time (Nart, 1982, p. 371).

Moreover, at this time, NIOEM was effectively closed down by having its budget cut and its staff relocated to different agencies. The head of NIOEM, a 36-year-old woman doctor, Orapun Methadilokul, remained in her position and continued to treat patients suffering from chronic lead poisoning.

\section{Lamphun, 1993-96}

Between 1993-94, a similar event developed in the Northern Region Industrial Estate, in the town of Lamphun, some $30 \mathrm{~km}$ from the regional capital of Chiang Mai. An estimated 11 to 23 factory workers and their children died from unexplained causes; however, there was now no specialist agency to research the deaths. Local workers believed the deaths were caused by lead poisoning or inhalation of solvents. However, local authorities blamed the deaths on AIDS, which is increasingly common in Lamphun. Indeed, a survey at the time revealed that 9 per cent of pregnant women in the province were HIV positive. Another possible cause of death was so-called 'Sudden Unexpected Nocturnal Death Syndrome', which has affected overseas Thai workers in mysterious circumstances, possibly related to a virus or toxins eaten from plastic rice containers.

The symptoms and circumstances of the deaths suggested industrial poisoning may be at least partly responsible. At least eight fatalities were workers who made electronic circuitry or glass lenses using solvents or soldering, and the two children who died suspiciously could have absorbed lead from breast feeding or physical contact with parents covered with dust. Most died suddenly in convulsions, which suggested solvent poisoning rather than nocturnal death or illnesses associated with AIDS (Gassert, 1985; Kalliokoski, 1986).

However, research into the cause of deaths was made difficult by the local custom of cremating bodies quickly, and also by the fact that solvent poisoning may be impossible to detect after death because of solvents may quickly evaporate or 
become absorbed by body fats. In addition, local doctors and academics explained that any incidence of AIDS was likely to be hidden by families because fears of social stigmatism. Yet for their part, local hospitals themselves apparently manipulated research by refusing to release the body of one dead worker for analysis in Bangkok; and by retracting an initial diagnosis of aluminium poisoning for a surviving female worker, leading to a legal case which she finally lost in 1996 (see also Theobald, 1995).

Most activism was organized by the so-called 'Lamphun Action Group' which had already campaigned about alleged pollution, and was composed of local residents, factory workers, and concerned academics in Bangkok and Chiang Mai who were natives of Lamphun. In particular, they sought advice from Dr Orapun of the defunct NIOEM who had been written to by workers suspecting illness from poisoning. National press (including a journalist born in Chiang Mai) ${ }^{4}$ campaigned to get her reinstated as an investigator of the deaths. In Bangkok, the newly-launched 'Toxic Watch Newsletter', also provided attention, and top rock-band Carabao (who had already campaigned on environmental issues) released a song about the deaths in Lamphun which described the fear and uncertainty associated with industrial estates in rural areas.

The dispute was largely unresolved until early 1994 when local journalists revealed that toxic waste had been dumped in a nearby wood because the estate had no central waste-treatment system. This caused immense embarrassment to the Industrial Estate Authority of Thailand, and they immediately undertook a nationwide audit of other estates. This, and other pressure eventually forced the government to authorize enquiries into industrial poisoning at Lamphun by selected experts, finally including Dr Orapun. However, in interview, she revealed she had been threatened with losing her job if she was critical of the estate. Despite the attention, industrial poisoning was never proven, and since then no long-term change of policy or consultation of local groups has been indicated by the government.

\section{DISCUSSION: ALLIANCES AND THE CONSTRUCTION OF RISK}

\section{The construction of risk}

The most obvious problem from the case study is the diversity of truth claims about the biophysical nature of risk. The conflicting accounts of AIDS, lead, and solvent poisoning are all plausible explanations for workers' deaths, and indeed are likely to have contributed in some way to health problems in both Samut Prakan and Lamphun. The available evidence, nonetheless, suggests that solvent poisoning may be the most likely explanation for most of the deaths in the factories because the symptoms suggest sudden inhalation of chemicals. However, most media and public debate focused on lead poisoning rather than solvent poisoning - apparently because it was first suggested by NIOEM's report in Samut Prakan, and because there is already a long history of chronic lead poisoning in electronics factories and mining

\footnotetext{
${ }^{4}$ Kamol Sukin of The Nation.
} 
sites in Southeast Asia. ${ }^{5}$ Indeed, some workers in both Samut Prakan and Lamphun had claimed compensation for alleged chronic lead poisoning before both disputes. Furthermore, the publication of the Committee for Primary Health Care of Thai NGOs is called Lead.

Part of the problem in not identifying solvent poisoning lay in the lack of medical expertise in northern Thailand to investigate new industrial hazards. The original plans for a national network of occupational heatlh centres under NIOEM would have produced this expertise, but were cancelled when NIOEM was effectively closed. Furthermore, the behaviour of local hospitals ${ }^{6}$ in resisting a full enquiry suggested they were influenced by their desire to win local contracts with the industrial estate to conduct regular health checks.

In addition, it was easier for all parties concerned to consider lead poisoning because it was the only potential cause of death for which there was 'hard' data in NIOEM's original report. As noted above, solvent poisoning may be impossible to detect even if full and immediate post mortems are conducted because of the speed with which chemicals dissipate. More importantly, perhaps, state agencies may have preferred to direct debates towards lead poisoning because it is easier to deny as a cause of death than solvents. Lead poisoning therefore represented a multivalent aspect of environmental discourse between the NGO activists and the state because it allowed both parties to pursue their political project of discrediting each other. However, the emergence of this multivalency - or discourse coalition (Hajer, 1995; Wynne, 1996) - in the case study did not help identify the most likely cause of death. This finding supports concerns about the epistemic fallacy of social movements; plus Wynne's argument that 'taking sides' in disputes about risk may not assist in the overall solution to the problem.

\section{The political representativeness of alliances}

The examples of Samut Prakan and Lamphun illustrate alliances between factory workers, local NGOs, national NGOs and concerned individuals such as academics, doctors and journalists. However, the evolving dispute led to a polarization of positions between full-time activists and the state, and a marginalization of individual experts. For example, the influence of Dr Orapun on the dispute was instrumental and represented a great personal risk to her own career. Orapun herself was already wellknown in Bangkok as a woman doctor and had already been reported in the press as working to protect factory workers. However, her suggestions about the nature of risk (solvent poisoning) generally took second precedence behind broader political campaigns to weaken the Board of Investment and the Industrial Estate Authority of Thailand; and did little to influence the nature of the official enquiries into poisoning.

\footnotetext{
${ }^{5}$ For example, in Kanjanaburi province, western Thailand, the Klity mine was found to be polluting local rivers with lead in 1998. Debates about lead still continue in Lamphun. In 1999, activists revealed that lead levels were high in waste water and blamed industry. Local authorities, however, claimed this was caused by inadequate disposal of batteries by local people (James Fahn, The Nation, personal communiction, 1999).

${ }^{6}$ Particularly the McCormick Hospital, which retracted its original diagnosis of aluminium poisoning on one patient from Lamphun.
} 
The alliances between factory workers and national campaigners also showed tensions between old and new social movements. The key purposes of the environmental campaign by national NGOs and the media were to question the government's broad commitment to industrialization without concern for the community. Yet somehow the short-term claims for pay rises, unionization and protection against poisoning by workers in the factories became second priority and were not met. The involvement of rock-band Carabao and its song about Lamphun, for example, suggested a romanticization of the conflict in terms of lost innocence in rural areas, and the uncertainty associated with high technology. ${ }^{7}$ This trend supports comments above from observers who have suggested that community development in Thailand may reflect the perception among some urban élites of lost Thai heritage, rather than immediate desires of workers (Rigg, 1991; Pasuk and Baker, 1995).

The impacts of the alliance on industrial regulation are unclear. Media attention to the deaths led to the exposure of waste dumping and the lack of centralized waste treatment in Thailand's industrial estates. However, the focus of debate on lead rather than solvent poisoning may have avoided targeting the most likely cause of death. Furthermore, public trust in the industrial estates plummeted after the conflict, leading to a sudden changeover of some 40 per cent of the Lamphun estate workforce in 1994, with most of the new workers being poor migrants from northeastern Thailand. Also, Dr Orapun suggested that the absence of further deaths (to date) in the estate might result more from practices like rotating workers between different stages of production rather than a committed long-term approach to safety. Again, therefore, the impact of the alliance may have been to strengthen the media criticism of the state in general, rather than enhance protection for workers most exposed to risks.

Finally, it is worth discussing the author's role himself in creating knowledge about the incidents. The author's own interest was in supporting the claims of workers against both industry and state. However, the magazine for whom the article was written (the Hong Kong-based Asia, Inc.) was owned by a prospective Thai politician ${ }^{8}$ and addressed a business readership. The official line encouraged by the magazine was of outrage against the state, rather than criticism of investors. Further, the magazine's editors from the USA wanted to present an image of fighting for justice even if they had not been to Thailand or understood the local culture. One such gesture resulted in the author being asked to telephone Lamphun after the death of yet another worker in 1994 and ask the bereaved family if the magazine could organize a post mortem. The telephone call - from a bustling Hong Kong office to a small village in northern Thailand - was met with incredulity and embarrassment, and the news that the body had already been cremated and that the family were in mourning.

In terms of impact, the magazine article written by the author was the first report to make the link between the closure of NIOEM in 1991 and the workers deaths in 1994. ${ }^{9}$ The immediate reaction was an angry protest from industrialists in Lamphun and an (incorrect) denial that a photograph of a polluting smokestack had not been

\footnotetext{
${ }^{7}$ Indeed, the potential class differences in popular music between luk thung (modern folk music from the rural Northeast) and pua chiwit (progressive pop from Bangkok) makes a fascinating topic for analysis in current environmental discourse in Thailand - see Ubonrath (1991).

${ }^{8}$ Sonthi Limthongkul, owner of the Manager publishing group and launcher of Asia's first Englishlanguage daily, Asia Times. Both Asia Times and Asia, Inc. were sold in the Thai financial crisis of 1997.

${ }^{9}$ The author first learnt of the link from Dara O'Rourke of UNDP, and then subsequent discussions with James Fahn of The Nation. The workers' deaths and uncertainty about environmental protection at the estate were the focus of several articles in both Thai and English-language media throughout 1994-95.
} 
taken at the estate. Later press releases from the Board of Investment and Industrial Estate Authority suggested the article may have influenced the decision to reinstall Dr Orapun as an adviser. However, one unexpected consequence might have been to increase debate about the uncertainty of biophysical risk, and the difficulties of proving solvent poisoning. ${ }^{10}$ One later press release by the Industrial Estate Authority talked of the difficulty of being certain. Furthermore, the governor of the Authority also wrote to the magazine to deny lead poisoning, in what seemed a deliberate attempt to direct attention away from solvents.

The results of these arguments between state, industry and campaigners seemed, however, to support two broad 'sides' to the dispute reflecting either the state's defence of industrialization against a multitude of uncertain and unprovable hazards; and the campaigners' general distrust and critique of industrialization and the government agencies that profit from it. These broader positions, or 'storylines' (after Hajer, 1995) reflect deeper divides in society rather than insights from expert individuals. They also indicate that the management of particular risks such as those occurring in the factories of Thailand may be better addressed by establishing longterm inclusive enquiries into problems rather than simply 'taking sides' between the different truth claims. As the rapid workforce turnover at the industrial estate showed, building trust in environmental management is not just good for workers' health but also for investment confidence and the creation of a skilled workforce.

\section{CONCLUSION}

This paper has looked critically at academic debates about the communicative action of environmental activism by assessing a case study of industrial poisoning in Thailand. The paper concludes by arguing that environmental activism alone is insufficient to address the concerns of poor people most affected by environmental risks. Political pluralism, in the form of greater public activism against the state, cannot be equated simply with the representation of plural environmental rationalities or the communication of accurate environmental knowledge to policy.

In Liberation Ecologies, for example, Peet and Watts (1996) argue in favour of social movements as an effective tool for representing local environmental perceptions and knowledge in policy. Escobar (1996, p. 56), writing in support of this approach claims this is "something entirely different from saying "There is no real nature out there" '. This paper disagrees by stating that a more in-depth and critical approach to environmental risk is necessary in order to ensure that poor people are represented in activism, and that the resulting policy addresses the risks that affect poor people most. In Thailand, this situation was illustrated for risks as potentially lethal as solvent poisoning.

The crucial problem that all environmental research and activism faces is the epistemic fallacy, or the misplaced belief that our experience of environmental processes may indicate their complex reality in ways independent of that experience. Academic debates favouring political pluralism or poststructural approaches to environmental perception have had significant success in signifying social diversity

\footnotetext{
${ }^{10}$ See the article, 'Proving something is safe is not an easy task', Bangkok Post 17th March 1996, which featured an interview with the governor of the Industrial Estate Authority of Thailand.
} 
and challenging historic dominating discourses of development. However, it is still necessary to acknowledge the continued impact of class systems under industrialization on social activism, and the difficulties of understanding biophysical reality independent of social experience. This is not to suggest that biophysical risks may be identified in a realist or absolute way, but to increase awareness of how environmental activism may replicate existing environmental discourse, or the political frames in which environmental conflicts are discussed.

Implictions for alliances between NGOs and other citizen groups include a need to see their influence on environmental policy as more than simply resource mobilization, or the empowerment of one 'side' against another. Instead, activists should acknowledge the pragmatic nature in which alliances emerge and produce environmental knowledge. Part of this is to examine critically the objectives of both activism and research, and the potential marginalization of less powerful voices in alliances (Chambers, 1997). In particular, researchers should not assume that environmentalism is a shared ideology across different social groups (Covey, 1995).

However, this paper should not be misconstrued as an attempt to weaken environmental activism or to exclude civil society in environmental policy. As Wynne (1996, p. 363) notes, 'it has been recognised for some time that sociological deconstruction of knowledge may find itself in unwelcome company, politically speaking'. Instead, this paper aims to strengthen the ability of activism to represent those most affected by risks. Poststructural deconstruction of dominating narratives through diverse debate is an essential part of building a democratic and effective environmental policy. But the existence of activism alone must not be mistaken for an accurate and equitable indication of environmental risks. ${ }^{11}$

\section{ACKNOWLEDGEMENTS}

Original research in 1994 was funded by the Chaiyong Limthongkul Foundation of Thailand, and Asia, Inc. magazine in Hong Kong. Subsequent research was funded by the Royal Society 20th IGC Fund and the Geography and Anthropology Research Division of the London School of Economics. The author is grateful for the assistance of Dara O'Rourke of UNDP; Kamol Sukin and James Fahn of The Nation; and Project for Ecological Recovery.

\section{REFERENCES}

Apffel, Marglin, F. and Marglin, S (ed) (1990). Dominating Knowledge: Development Culture and Resistance. Oxford: Clarendon Press.

Bhaskar, R. (1986). Scientific Realism and Human Emancipation. London: Macmillan.

Boehmer-Christiansen, S. (1994). 'Global climate protection policy: the limits of scientific advice part II', Global Environmental Change, 4(3).

\footnotetext{
${ }^{11}$ In this point the paper makes a similar conclusion to Putzel (1997) who argues that the existence of civic associations should not be mistaken for their content in terms of creating democratization and social capital.
} 
Brown, K. and Ashman, A. (1996). 'Participation, social capital and intersectoral problem solving: African and Asian cases', IDR Reports, 12(2), 13-23.

Chambers, R. (1997). Whose Reality Counts? Putting the Last First. London: Intermediate Development.

Covey, J. (1995). 'Accountability and effectiveness in NGO policy alliances'. In Edwards, M. and Hulme, D. (eds) Non-Governmental Organisations - Performance and Accountability: Beyond the Magic Bullet. London: Earthscan, pp. 167-182.

Daly, J. (1991). 'Does a constructivist view require epistemological relativism? A response to Turnbull', Social Studies of Science, 21(3), 568-571.

Escobar, A. (1996). 'Constructing nature: elements for a poststructural political ecology'. In Peet, R. and Watts, M. (eds) Liberation Ecologies. London: Routledge, pp. 46-68.

Eyerman, R. and Jamison, A. (1991). Social Movements: a Cognitive Approach. Cambridge: Polity.

Forsyth, T. (1994). 'Shut up or shut down: How a Thai medical agency was closed after it questioned worker safety at a factory owned by Thailand's largest employer', Asia, Inc., 3(4), 30-37.

Funcowicz, S. and Ravetz, J. (1993). 'Science for the post-normal age', Futures, 25(7), $739-755$

Gandy, M. (1999). 'Rethinking the ecological leviathan: environmental regulation in an age of risk', Global Environmental Change, 9(1), 59-70.

Gassert, T. (1985). Health Hazards in Electronics: a Handbook. Hong Kong: Asia Monitor Resource Centre.

Guha, R. and Martinéz-Alier, J. (1997). Varieties of Environmentalism. London: Earthscan.

Hajer, M. (1995). The Politics of Environmental Discourse: Ecological Modernisation and the Policy Process. Oxford: Clarendon.

Hewison, K (ed) (1997). Political Change in Thailand: Democracy and Participation. London: Routledge.

Hirsch, P. (1997). Seeing Forests for the Trees: Environmentalism in Thailand. Chiang Mai: Silkworm Press.

Hirsch, P. and Lohmann, L. (1989). 'Contemporary politics of environment in Thailand', Asian Survey, 89(4), 439-453.

Irwin, A. (1995). Citizen Science: A Study of People, Expertise, and Substainable Development. London: Routledge.

Jackson, C. (1995). 'Radical environmental myths: a gender perspective', New Left Review, 210, 124-140.

Jasanoff, S. (1996). 'Beyond epistemology: relativism and engagement in the politics of science', Social Studies of Science, 26(2), 393-418.

Kalliokoski, P. (1986). 'Solvent containing processes and work practices: environmental observations'. In Riihimäki, V. and Ulfvarson, U. (eds) Safety and Health Aspects of Organic Solvents, (Progress in Clinical and Biological Research vol. 220). New York: Alan R. Liss Inc., pp. 21-30.

Leach, M. and Mearns, R. (eds) (1996). The Lie of the Land: Challenging Received Wisdom on the African Environment. Oxford: James Currey.

Long, N. and Long, A. (eds) (1992). Battlefields of Knowledge: The Interlocking of Theory and Practice in Social Research and Development. London: Routledge.

Murdoch, J. and Clark, J. (1994). 'Sustainable knowledge', Geoforum, 25(2), 115-132.

Nart, Tuntawiroon (1982). 'Environmental impact of industrialization in Thailand', Contemporary Southeast Asia, 4(3), 369-380. 
Paehlke, R. and Torgerson, D. (eds) (1990). Managing Leviathan: Environmental Politics and the Administrative State. Lewiston: Broadview Press.

Pasuk, P. and Baker, C. (1995). Thailand: Economy and Politics. Kuala Lumpur: Oxford University Press.

Peet, R. and Watts, M. (eds) (1996). Liberation Ecologies: Environment, Development, Social Movements. London: Routledge.

Ponna, W (ed) (1993). New Social Movements in the South: Empowering the People. London: Zed.

Princen, T., Finger, M. and Manro, J. (1994). 'Transitional linkages'. In Princen, T. and Finger, M. (eds) Environmental NGOs in World Politics: Linking the Local and the Global. London: Routledge.

Putzel, J. (1997). 'Accounting for the dark side of social capital', Journal of International Development, 9(7), 939-949.

Quigley, K. (1995). 'Environmental organisations and democratic consolidation in Thailand', Crossroads, 9(2), 1-30.

Rigg, J. (1991). 'Grass-roots development in Thailand: a lost cause?', World Development, 19(2/3), 199-211.

Rigg, J. (1994). 'Alternative development strategies, NGOs and the environment in Thailand: a critique', Thailand Environment Institute Quarterly Environment Journal, 2(2), 16-26.

Roe, E. (1995). 'Except Africa: postscript to a special section on development narratives', World Development, 23(6), 1065-1069.

Searle, J. (1995). The Construction of Social Reality. London: Allen Lane.

Spivak, G. C. (1988). 'Can the subaltern speak?'. In Nelson, C. and Grossberg, L. (eds) Marxism and the Interpretation of Culture. London: Macmillan, pp. 271-313.

Theobold, S. (1995). Pressure Points and Industrialisation: a Gender Analysis Framework of the Northern Region Industrial Estate, Thailand. MA Thesis, University of East Anglia, Norwich.

Turnbull, D. (1991). 'Local knowledge and "absolute standards": a reply to Daly', Social Studies of Science, 21(3), 571-573.

Ubonrath, S. (1991). 'The environment and popular culture in Thailand'. In Southeast Asian Affairs: 1991. Singapore: Institute of Southeast Asian Studies, pp. 298-308.

Wynne, B. (1996). 'SSK's identity parade: signing-up, off-and-on', Social Studies of Science, 26(2), 357-391.

Yearley, S. (1996). Sociology, Environmentalism, Globalization. London: Sage. 